\title{
Attraction and repulsion forces in melt-textured and sintered YBCO-superconductors: comparative study
}

Fuerzas de atracción y repulsión en superconductores YBCO texturizados y sinterizados: un estudio comparativo

\author{
Diego Andrés Arias-Arana (id ${ }^{*}$, Juan Diego Rojas-Zambrano (i) ${ }^{1}$, Álvaro Mariño-Camargo (i) 1 \\ ${ }^{1}$ Grupo de Superconductividad y Nuevos Materiales, Departamento de Física, Universidad Nacional de Colombia. Cra 45, Bogotá. C. P. \\ 111321. Bogotá, Colombia.
}

\section{CITE THIS ARTICLE AS:}

D. A. Arias, J. D. Rojas and A.

Muriño. "Attraction and

repulsion forces in

melt-textured and sintered

YBCO-superconductors: a

comparative study", Revista

Facultad de Ingeniería

Universidad de Antioquia, no.

96, pp. 44-50, Jul-Sep 2020.

[Online]. Available: https:

//www.doi.org/10.17533/

udea.redin. 20191044

\section{ARTICLE INFO:}

Received: February 14, 2019 Accepted: October 23, 2019

Available online: October 23, 2019

\section{KEYWORDS:}

Applied research; temperature; measurement

Investigación aplicada; temperatura; medición
ABSTRACT: In this paper, we measure the attraction (suspension) and repulsion (levitation) forces produced by the interaction between a permanent magnet and different bulk superconductors. The measurements of the interaction force HTS-PM were carried out with a relatively simple technique developed by us, which is reproducible, reliable and low cost. The obtained results were analyzed with the Bean's critical-state model assuming a uniform magnetic field applied to the superconductor. Two superconducting samples of $\mathrm{YBa}_{2} \mathrm{Cu}_{3} \mathrm{O}_{7-\delta}$ (YBCO) prepared by solid-state reaction method and by the melt-textured growth method (MTG) were used. Both samples presented a different hysteresis behaviour in the field cooling $(F C)$ and zero field cooling $(Z F C)$ regimes. Levitation and suspension phenomena were observed in the MTG sample; however, the sintered sample (S) with Oxygen deficiencies $(\delta>0.15)$ displayed a slight levitation force but did not show a suspension force, the latter one attributed to a more efficient magnetic flux pinning. Additionally, the critical current density of both samples was determined from the maximum gap of the force $(\triangle F)$ in the $F C$ regime. The obtained values were between $43.00 \mathrm{~A} / \mathrm{cm}^{2}$ and $2,758 \mathrm{~A} / \mathrm{cm}^{2}$ for the sintered and MTG samples, respectively. These values show a remarkable difference between sintered and MTG samples like that observed from magnetization measurements, which indicate that attraction and repulsion force measurements could provide a rapid and reliable characterization method of polycrystalline superconducting samples.

RESUMEN: En este artículo medimos las fuerzas de atracción (suspensión) y repulsión (levitación) producidas por la interacción entre un imán permanente y diferentes superconductores. Las medidas de la fuerza de interacción HTS-PM fueron realizadas en un dispositivo sencillo, confiable y de bajo costo. Los resultados obtenidos fueron analizados utilizando el Modelo de Estado-Crítico propuesto por Bean bajo la suposición de un campo magnético uniforme aplicado al superconductor. Se utilizaron dos muestras superconductoras de $\mathrm{YBa}_{2} \mathrm{Cu}_{3} \mathrm{O}_{7-\delta}$ preparadas por el método de reacción de estado sólido (S) y por el método de texturizado y fundido (MTG). Las muestras presentaron diferente comportamiento de histéresis en los regímenes de field cooling (FC) y zero field cooling (ZFC). Los fenómenos de levitación y suspensión se observaron en la muestra MTG; sin embargo, la muestra sinterizada con deficiencias de oxígeno $(\delta>0,15)$ sólo mostró una ligera fuerza de levitación, aunque no de suspensión, esta última propiedad atribuida a un anclaje del flujo magnético más eficiente. Se determinó la densidad de corriente crítica en ambas muestras a partir del máximo gap de la fuerza $(\triangle F)$ en el régimen $F C$. Los valores obtenidos están entre $43,00 \mathrm{~A} / \mathrm{cm}^{2}$ y $2.758 \mathrm{~A} / \mathrm{cm}^{2}$ para la muestra sinterizada y MTG respectivamente. Las diferencias observadas entre las dos muestras coinciden con las determinadas a partir de medidas de magnetización, lo cual indica que estas medidas podrían utilizarse para una rápida caracterización de muestras sunerconductoras policristalinas.

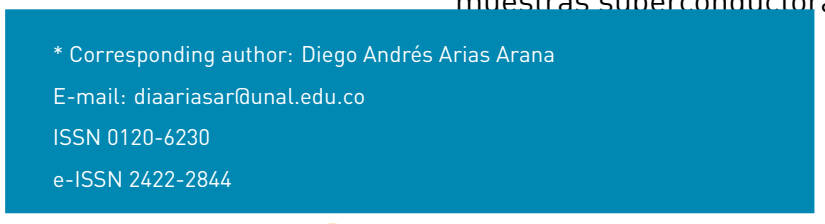




\section{Introduction}

The interaction between high Tc superconductors (HTS) and a permanent magnet (PM) shows the levitation (repulsion) and suspension (attraction) phenomena, which have been a subject of great interest in the last three decades, due to the potential applications such as energy storage systems [1-3], levitating vehicles $[4-8]$ and high-speed bearings $[9,10]$. The interaction forces between a superconductor and a permanent magnet (HTS-PM system) can be measured in the three-dimensions [11-13]; however, the levitation and suspension phenomena in an HTS-PM system are possible when the force has the opposite direction of gravity, which compensates the weight of the HTS or the PM. Thus, the most common measurement of this type of interaction is the one carried out vertically.

One of the main characteristics of the interaction forces in an HTS-PM system is the hysteresis loops present when the superconductor and the magnet are moving relative to each other in any of the two regimes ZFC or FC. In all the cases, the force is hysteretic because of the hysteresis in magnetization $[5,14-16]$. The hysteresis behaviour also depends on several factors like the fabrication method $[17,18]$, volume and geometry of both, superconductor and magnet, the relative velocity between magnet and superconductor, type of magnet [19] and the configuration of the HTS-PM system [20, 21]. Several approximations have been proposed to explain this type of interactions, like frozen-image method [22-24], also different analytical and numerical solutions have been studied using the critical state model for some particular configurations [25-30].

The measurements of the interaction force HTS-PM were carried out with a relatively simple technique developed here, which is reproducible, reliable and low cost based on the system developed by S.O.Valenzuela et al. [31]. This technique allows doing qualitative predictions about quality of the superconducting material for different applications. The obtained results were analyzed using the Bean's critical-state model in the approximation of a uniform field applied to the superconductor [32-34]. In spite of our main goal was the qualitative determination of some properties of superconductors, the critical current values determined using this technique showed remarkable differences between both samples analyzed, as those obtained by other methods for example by magnetization measurements using a vibrating sample magnetometer.

\section{Theoretical framework}

We studied the attraction and repulsion forces produced by the interaction between a HTS and a PM when they are moving a distance $z$ relative to each other. In this case, we consider that supercurrents fill a volume $V$ where the magnetic field is uniform enough in order to define a mean magnetization $M$. A simplified relation between the force along z-axis $\left(F_{z}\right)$ and the vertical component of applied magnetic field $\left(H_{z}\right)$ can be found and is given by Equation $1[31,35]$.

$$
F_{z}=\mu_{0} M_{z} \frac{\partial H_{z}}{\partial z} V
$$

where $M_{z}$ is the constant magnetization in the z-axis direction, $\frac{\partial H_{z}}{\partial z}$ represents the field gradient along the $z$ direction, and $V$ the volume of the sample. The values of the magnetic field and its derivative are assumed constant over the HTS and the demagnetization effects due to finite dimensions have been neglected [32-34]. For a permanent magnet (PM), its magnetic field $H(z)$ decreases when the distance $z$ HTS-PM increase, therefore $\frac{\partial H_{z}}{\partial z}$ is always negative. Since $V$ and $\mu_{0}$ are positive, then, according to Equation 1, the sign of $F_{z}$ is opposite to the sign of $M_{z}$.

The relations between the magnitude of the current density and the magnetization for a rectangular-like and disk-like geometry are given by Equations 2 and 3 respectively.

$$
j_{c}=\frac{2 \triangle M}{d}
$$

and

$$
j_{c}=\frac{3 \triangle M}{R}
$$

Where $d$ is the thickness of the rectangular sample and $R$ is the radius of the disk-shaped sample.

\section{Experimentation}

Figure 1 shows the experimental setup used to measure the interaction forces in the HTS-PM system [29]. A digital balance (Citizen CY 204) was used, with a resolution of $10^{-4}$ $\mathrm{g}$ and a maximum capacity of $220 \mathrm{~g}$. A permanent magnet of $\mathrm{Nd}-\mathrm{Fe}-\mathrm{B}$ with dimensions $40 \times 25 \times 5 \mathrm{~mm}$, was fixed $7 \mathrm{~cm}$ above the center of the balance's plate. The system also includes an endless screw, which allows high accuracy in the distance measurements. The superconducting samples used, were permanently immersed in liquid nitrogen and attached to the polycarbonate arm. In our case, the applied field at the sample increase when the HTS is descending (descending direction) and decrease when the HTS is moving in the opposite direction lascending direction).

In order to move them vertically at a constant velocity (in this case at $0.2 \mathrm{~mm} / \mathrm{s}$ ), we use a DC electric gear motor. 


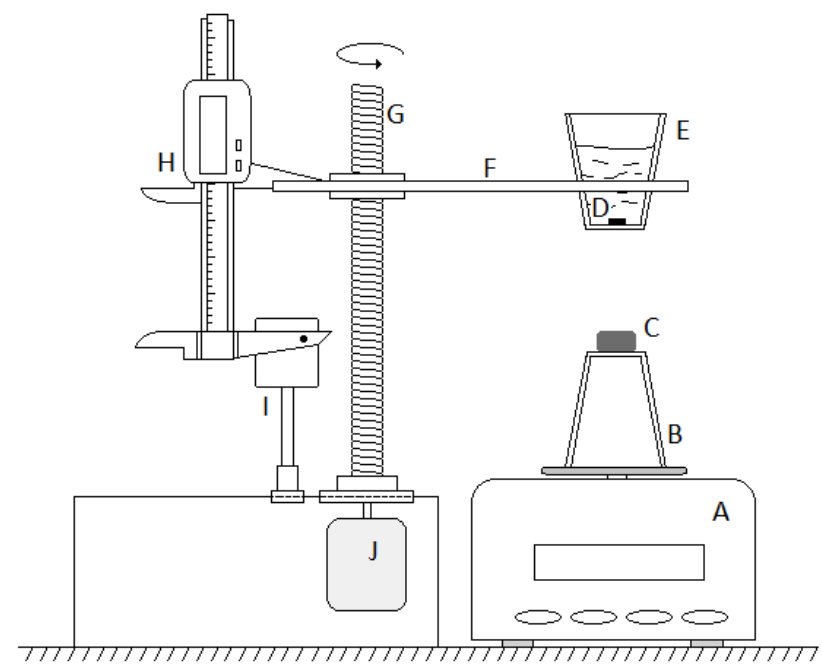

Figure 1 Experimental setup: (A) Electronic balance with digital display, (B) pan of the balance, $(C)$ neodymium permanent magnet, (D) superconducting sample, (E) vessel with liquid nitrogen, (F) polycarbonate arm, (G) endless screw, $(H)$ digital Vernier caliper, (I) support for the digital caliper, (J) DC electric gear motor

A digital Vernier, with a resolution of $0.01 \mathrm{~mm}$, was used to measure the relative distance HTS-PM. The balance properly calibrated displays positive and negative values when the force is repulsive and attractive respectively. The ascent and descent measurements were carried out in a continuous manner in the FC and ZFC regimes for each sample. All of the measurements were performed cyclically from a distance of $1 \mathrm{~mm}$ between HTS and PM, up to a maximum distance of approximately $45 \mathrm{~mm}$.

The superconducting disk-shaped sample (YBCO-123) with diameter $10 \mathrm{~mm}$ and thickness $4 \mathrm{~mm}$ was produced by the solid-state reaction method, from $\mathrm{Y}_{2} \mathrm{O}_{3}, \mathrm{CuO}$ and $\mathrm{BaO}$ high purity oxides in stoichiometric quantities and mixed in a Zirconium balls mill. The mix was annealed at $860^{\circ} \mathrm{C}$ and oxygenated in $\mathrm{O}_{2}$ flux at $500^{\circ} \mathrm{C}$ during different times [36]. A second rectangular sample with dimensions $14 \times 10 \times 2 \mathrm{~mm}$ was produced by the Melt-Textured Growth (MTG) process [37]. The above mentioned neodymium permanent magnet was used in both cases.

\section{Results and discussion}

Figures 2 and 3 show the behaviour of the force as a function of the distance HTS-PM for the texturized (MTG) and sintered samples, respectively. The hysteresis curves show that the behaviour of the force as a function of the distance and its maximum value depends on the increasing or decreasing of the relative distance HTS-PM and on the cooling process ZFC or FC regimes (It is worth to note that in the ZFC regime the cooling of the sample was done removing completely the permanent magnet of the setup). Table 1 presents the maximum values of the force determined for both samples experimentally in the FC regime, and other values obtained using the Equation 1. As observed, the force is greater by two orders of magnitude in the texturized sample (MTG) than in the sintered one. The observed hysteretic behaviours

Table 1 Experimental values for both samples in FC regimen

\begin{tabular}{lllll}
\hline & $\boldsymbol{z}(\mathbf{m m})$ & $\boldsymbol{\mu}_{\mathbf{0}} \frac{\partial \boldsymbol{H}}{\partial \boldsymbol{z}}(\mathrm{T} / \mathrm{m})$ & $\boldsymbol{V}\left(\mathbf{c m}^{3}\right)$ & $\triangle \boldsymbol{F}(\mathbf{m N})$ \\
\hline & $\pm 0.1 \mathrm{~mm}$ & $\pm 0.05 \mathrm{~T} / \mathrm{m}$ & $\pm 0.01 \mathrm{~cm}^{3}$ & $\pm 0.01 \mathrm{mN}$ \\
Sint. & 12.0 & 7.44 & 0.38 & 2.22 \\
MTG. & 10.0 & 8.88 & 0.28 & 240.00 \\
\hline
\end{tabular}

are related to hysteresis in the magnetization $(\mathrm{M})$ of the sample. For type II superconductors, a magnetic flux $B$ can penetrate from its surface when a magnetic field $H$ is applied. This produces a magnetization $M=B / \mu_{0}-H$ in the material. On the other side, since the applied field decreases with the distance to the permanent magnet, its gradient is negative (Figures 6 a and b); then according to Equation 1, the force has an opposite sign than the magnetization.

At point $\mathrm{A}$ of Figure $2 \mathrm{a}$, the hysteresis curve for the MTG sample in the ZFC regimen starts with positive values of the force $(M<0)$ in the ascending direction; this is due to the screening of the magnetic flux in the material; in this region, levitation of the sample is possible since the magnitude of the interaction force is greater than the sample's weight $\left(\approx 16 \times 10^{-3} \mathrm{~N}\right)$. As the distance increases, the force decreases down to zero at point $\mathrm{B}$. In this point, the field inside the material as well as the applied field has decreased enough to annihilate the magnetization ( $M=0$ ). At point $\mathrm{C}$, the applied field decreases and the trapped field is larger, making the magnetization positive $(M>0)$; here the maximum value of the force is $-43.8 \mathrm{mN}$, thus suspension is possible. At point $D$ the force tends to zero because the permanent magnet's field decreases. As predicted by macroscopic modeling of magnetization and levitation in high Tc superconductors in the ZFC regimen, we also observed that the force is larger in the ascending path than in the descending one. This behaviour is related with the fact that in the descending direction, far away from magnet, there are not currents inside the superconductor and $M$ is almost zero.

The $\mathrm{FC}$ regimen (Figure $2 \mathrm{~b}$ ) can be explained in the same way as the ZFC. However, it is worth to note that in the $\mathrm{FC}$ regimen the sample was cooled at a given position above the PM and just after cooled it was moved. Only if the superconductor is moved, once already cooled, currents penetrate inside [38, 39]. 
An increase of the maximum force magnitude in the FC regimen compared to ZFC case is observed. In this regime, the trapped flux would be larger, which implies an increase in the magnitude of $M[40]$.

In Figure 3a (ZFC regimen), the hysteresis curve for the sintered sample is shown. At point $A^{\prime}$ in the ascending direction the force displayed negative values $(M>0)$. When the superconductor moves away the magnitude of the force decreases down to zero at point B', where the field inside the material is equal to the applied one ( $M=0)$. At point $\mathrm{C}^{\prime}$ the force is positive $(M<0)$ due to the screening of the magnetic flux. As the superconductor moves away the magnetic field of the magnet, it decreases causing the interaction force tends to zero, as observed at point 'D'. The suspension and levitation phenomena were not observed in this case, since the interaction force is weaker than the weight of the sintered sample $\left.1 \approx 24 \times 10^{-3} \mathrm{~N}\right)$. In both cases, a hysteretic behaviour

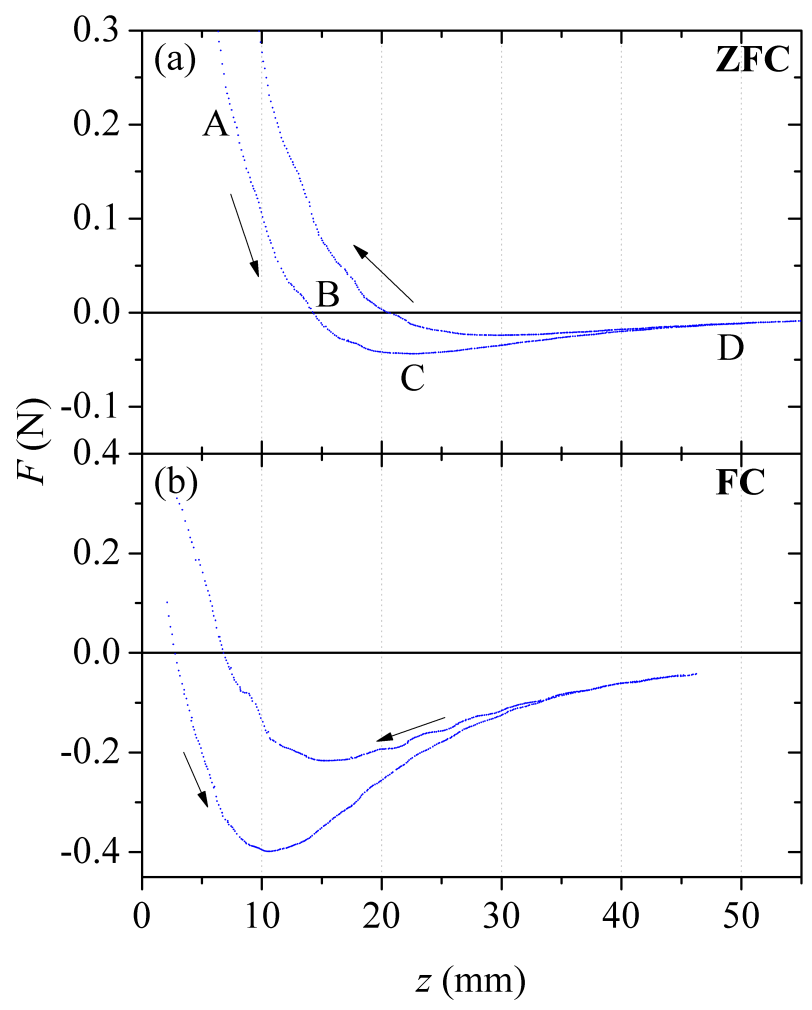

Figure 2 Force vs. distance HTS - PM for a texturized YBCO sample in the $\mathrm{ZFC}$ and $\mathrm{FC}$ regimens

was displayed with maximum negative values, which correspond to a maximum attractive force. The arrows show the direction of the relative displacement HTS-PM.
As displayed in Table 2, the $j_{c}$ values obtained from

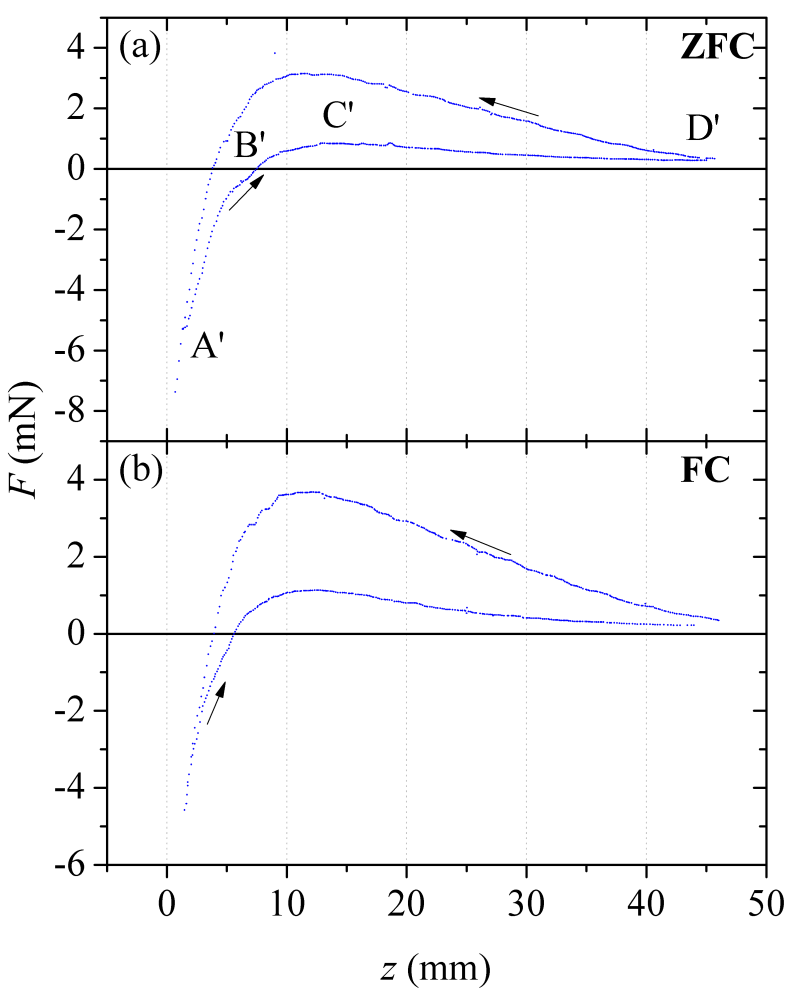

Figure 3 Force vs. distance between an YBCO sintered superconductor and a Permanent Magnet in the ZFC and FC regimens. A hysteretic behaviour was observed in both cases.

The maximum positive values correspond to a maximum repulsive force. The arrows show the direction of the relative displacement HTS-PM

Table 2 Comparison between $j_{c}$ values determined from force and magnetization measurements. $j_{C F}$ and $j_{c M}$ were obtained from $\triangle F$ and $\triangle M$ measurements, respectively

\begin{tabular}{lllll}
\hline SAMPLES & $\triangle \boldsymbol{F}$ & $\triangle \boldsymbol{M}$ & $\boldsymbol{j}_{\boldsymbol{c} \boldsymbol{F}}$ & $\boldsymbol{j}_{\boldsymbol{c} \boldsymbol{M}}$ \\
\hline & $\pm 0.01 \mathrm{mN}$ & $\pm 50 \mathrm{~A} / \mathrm{m}$ & $\pm 5 \mathrm{~A} / \mathrm{cm}^{2}$ & $\pm 100 \mathrm{~A} / \mathrm{cm}^{2}$ \\
SINT & 2.22 & 71,620 & 43.00 & 3,900 \\
MTG & 240.00 & 124,560 & 2,758 & 31,300 \\
\hline
\end{tabular}

$\triangle F$ measurements $\left(j_{c F}\right)$ are smaller than those $\left(j_{c M}\right)$ obtained from magnetization measurements $\triangle M$, using a Vibrating-Sample Magnetometer. The uniform field approximation used to determine the $j_{c}$ values could be one of the main reason of the observed differences. However, in both cases for the two types of superconducting samples analyzed, it is possible to observe a remarkable difference between sintered and texturized samples. It is worth highlighting that the method we used for determination of $j_{c}$ allows us to 
observe differences as those obtained from magnetization measurements for samples prepared by different routes. Figure 4 shows the X-ray diffraction pattern for the sintered sample, which presents the characteristic peaks and intensity relations of the YBCO-123 superconducting phase, with lattice parameters $a=$ $(3.824829 \pm 0.000863) \AA, b=(3.883515 \pm 0.001103) \AA$ and $c=(11.688500 \pm 0.002617) \AA$, as determined by Rietveld refinement. Small peaks from other non-superconducting phases in the material are also shown $[41,42]$. Figure 5 shows the $X$-ray

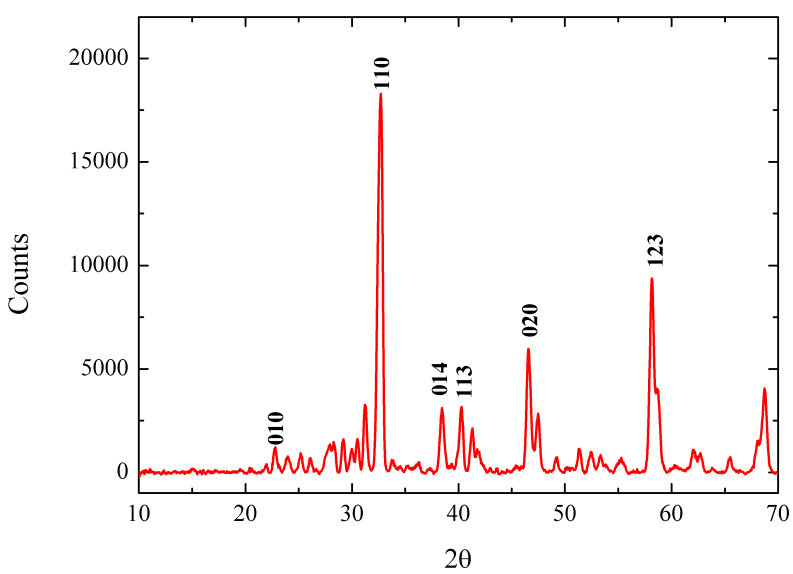

Figure 4 X-ray diffraction pattern of sintered sample

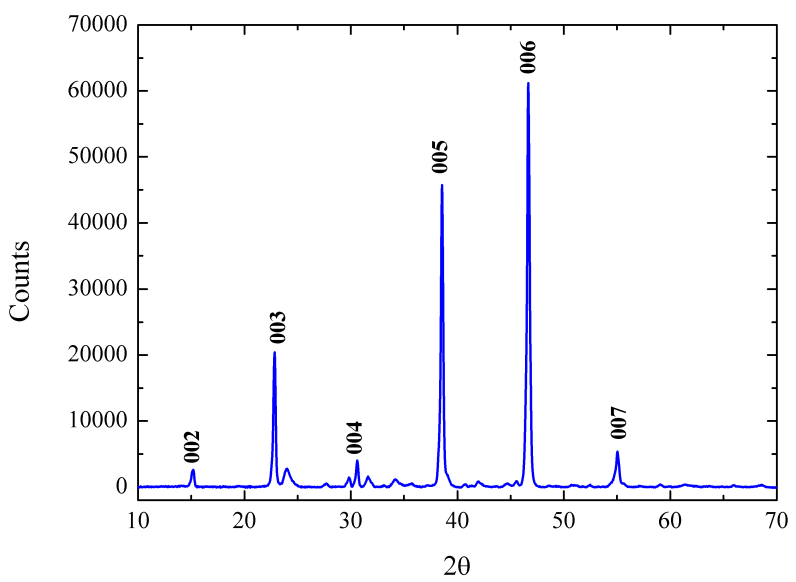

Figure 5 X-ray diffraction pattern of the melt-textured sample

diffraction pattern for the texturized sample (MTG), which presents the characteristic peaks and intensity relations corresponding to the YBCO-123 superconducting phase, with lattice parameters $a=$

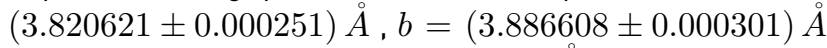
and $c=(11.685328 \pm 0.000408) \AA$, determined by
Rietveld refinement. It is noticeable a preferential growth of the sample along the $c$-axis, corresponding to the (001) planes [43, 44]. The Oxygen contents in both samples were obtained from the lattice parameters [45-47]. The obtained values are $\delta>0.15$ and $\delta \leq 0.10$ for the sintered and texturized samples, respectively, which agrees with the superconducting behaviour observed in these samples. Figure 6 a and $b$ show both the magnetic field of the permanent magnet and the corresponding field gradient respectively, which were used to determine the magnetization of the samples (Equation 1), and the $j_{c F}$ values (Equations 2 and 3).

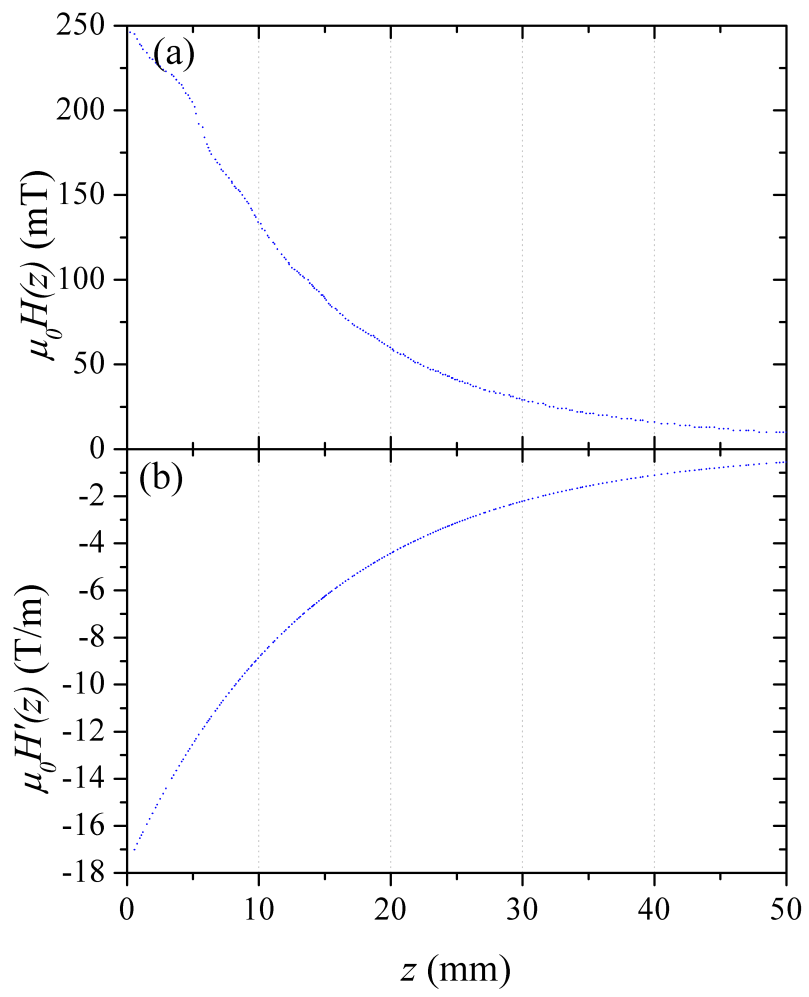

Figure 6 (a) Magnetic field of the permanent magnet used in the experiment as a function of distance and (b) the corresponding field gradient

\section{Conclusions}

The measurements of the interaction force HTS-PM were carried out with a relatively simple technique developed here, which is reproducible, reliable and low cost. This technique allows determining qualitatively some properties of the superconducting material for different applications. The experimental results were analyzed by using the Bean's critical-state model for the case of a 
uniform field applied to the superconductor.

The hysteresis phenomenon of the force as a function of distance, because of the hysteresis in magnetization, was observed for both analyzed samples in the ZFC and FC regimes.

For the texturized (MTG) sample with efficient pinning centers, it is possible to observe both levitation and suspension phenomena. Levitation is a consequence of the magnetic flux exclusion $(M<0)$ and suspension a consequence of the trapped flux inside the material ( $M>0$ ). The interaction force was smaller by two orders of magnitude for the sintered sample with an Oxygen content of approximately $0.55(\delta>0.15)$, than the texturized sample with $\delta<0.10$. On the other side, $F(z)$ measurements have allowed determining the value of the critical current density $\left(j_{c}\right)$, which, provided a simply method to establish, as in this case, characteristics and differences between superconductors prepared using different routes.

The critical current values determined using this technique showed remarkable differences between both analyzed samples, being higher in MTG sample than in the sintered one. A similar behaviour of $j_{c}$ was obtained by using other methods like magnetization measurements.

It is well-known that the ability to carry current $\left(j_{c}\right)$ by a superconductor is strongly influenced by the method of preparation. The observations made with the developed system clearly show these differences, which, together with the reproducibility and reliable characteristics mentioned above, allow us to use this system for the qualitative determination of some superconducting properties. On the other side, the experimental results found out, fit with different analytical and numerical solutions which, have been studied using the critical state model and experimental results obtained by other authors $[21,48]$.

\section{Declaration of competing interest}

None declared under financial, professional and personal competing interests.

\section{Acknowledgments}

We wish to thank the Universidad Nacional de Colombia for financial support through the program "Semilleros de Investigación" and to the "grupo de superconductividad y Nuevos Materiales" of the Physics Department for the academic support.

\section{References}

[1] K. Nagashima, H. Seino, N. Sakai, and M. Murakami, "Superconducting magnetic bearing for a flywheel energy storage system using superconducting coils and bulk superconductors," Physica C: Superconductivity, vol. 469, no. 15-20, October 152009. [Online]. Available: https://doi.org/10.1016/j.physc.2009.05.245

[2] Y. Han, B. Park, S. Jung, and S. Han, “Study of superconductor bearings for a $35 \mathrm{kwh}$ superconductor flywheel energy storage system," Physica C: Superconductivity, vol. 483, December 142012. [Online]. Available: https://doi.org/10.1016/j.physc.2009.05.245

[3] Y. Arai, H. Seino, K. Yoshizawa, and K. Nagashima, “Development of superconducting magnetic bearing with superconducting coil and bulk superconductor for flywheel energy storage system," Physica C: Superconductivity, vol. 494, November 15 2013. [Online]. Available: https://doi.org/10.1016/j.physc.2009.05.245

[4] R. Byer, R. Begley, and G. Stewart, "Superconducting, magnetically levitated merry-go-round," American Journal of Physics, vol. 42, no. 2, February 1974. [Online]. Available: https://doi.org/10.1119/1. 1987626

[5] J. Wang and et al, "The first man-loading high temperature superconducting maglev test vehicle in the world," Physica C: Superconductivity, vol. 378-381, no. Part 1, October 1 2002. [Online]. Available: https://doi.org/10.1016/S0921-4534(02)01548-4

[6] W. Wang and et al, "Levitation characteristics of a high-temperature superconducting maglev system for launching space vehicles," Physica C: Superconductivity and its Applications, vol. 455, no. 1-2, May 1 2007. [Online]. Available: https://doi.org/10.1016/j.physc. 2007.01.025

[7] Z. Deng and et al, "Studies on the levitation height decay of the high temperature superconducting maglev vehicle," Physica C: Superconductivity and its Applications, vol. 463-465, October 12007. [Online]. Available: https://doi.org/10.1016/j.physc.2007.02.050

[8] Z. Deng and et al, "Superconducting bulk magnet for maglev vehicle: Stable levitation performance above permanent magnet guideway," Materials Science and Engineering: B, vol. 151, no. 1, June 152008. [Online]. Available: https://doi.org/10.1016/j.mseb.2008.03.011

[9] Y. Han and et al, "Design and characteristics of a superconductor bearing," IEEE Transactions on Applied Superconductivity, vol. 15, no. 2, June 2005. [Online]. Available: https://doi.org/10.1109/TASC. 2005.849623

[10] A. Cansiz and I. Yildizer, "The design considerations for a superconducting magnetic bearing system," Cryogenics, vol. 63, September 2014. [Online]. Available: https://doi.org/10.1016/j. cryogenics.2014.06.006

[11] S. Wang and et al, “An update high-temperature superconducting maglev measurement system," IEEE Transactions on Applied Superconductivity, vol. 17, no. 2, June 2007. [Online]. Available: https://doi.org/10.1109/TASC.2007.899257

[12] S. Chen and et al, "A new 3d levitation force measuring device for rebco bulk superconductors," Physica C: Superconductivity and its Applications, vol. 496, January 15 2014. [Online]. Available: https://doi.org/10.1016/j.physc.2013.07.004

[13] X. Zhang, Y. Zhou, and J. Zhou, "Three-dimensional measurements of forces between magnet and superconductor in a levitation system," Physica C: Superconductivity and its Applications, vol. 467, no. 1-2, December 1 2007. [Online]. Available: https: //doi.org/10.1016/j.physc.2007.09.010

[14] F. Moon, M. Yanoviak, and R. Ware, "Hysteretic levitation forces in superconducting ceramics," Applied Physics Letters, vol. 52, no. 18, June 4 1988. [Online]. Available: https://doi.org/10.1063/1.99700

[15] T. Torng and Q. Chen, “Magnetic forces for type II superconductors in a levitation field," Journal of Applied Physics, vol. 73, no. 3, 1993. [Online]. Available: https://doi.org/10.1063/1.353286

[16] J. Wang and et al, "Levitation force of a ybacuo bulk high temperature superconductor over a ndfeb guideway," IEEE Transactions on Applied Superconductivity, vol. 11, no. 1, march 2001. [Online]. Available: https://doi.org/10.1109/77.920136

[17] S. Jin and et al, “Large magnetic hysteresis in a melt-textured 
Y-Ba-Cu-O superconductor," Applied Physics Letters, vol. 54, no. 6, March 1989. [Online]. Available: https://doi.org/10.1063/1.101464

[18] B. Savaskan, E. Taylan, S. Celik, K. Ozturk, and E. Yanmaz, "Investigation on the levitation force behaviour of malic acid added bulk $\mathrm{MgB}_{2}$ superconductors," Physica C: Superconductivity, vol. 502 , July 15 2014. [Online]. Available: https://doi.org/10.1016/j.physc. 2014.04.032

[19] X. Zhang, Y. Zhou, and J. Zhou, "Influences of permanent magnets temperature characteristic on the levitation force of $\mathrm{YBaCuO}$ bulk superconductors," Journal of Superconductivity and Novel Magnetism, vol. 25, no. 4, pp. 857-860, May 2012.

[20] J. Zhou, X. Zhang, and Y. Zhou, "Temperature dependence of levitation force and its relaxation in a hts levitation system," Physica C: Superconductivity, vol. 470, no. 5-6, March 1 2010. [Online]. Available: https://doi.org/10.1016/j.physc.2009.12.070

[21] C. Navau and A. Sanchez, "Magnetic levitation of superconductors in the critical state," Physical Review B, vol. 58, no. 2, July 11998. [Online]. Available: https://doi.org/10.1103/PhysRevB.58.963

[22] A. Kordyuk, "Magnetic levitation for hard superconductors," Journal of Applied Physics, vol. 83, no. 1, June 4 1998. [Online]. Available: https://doi.org/10.1063/1.366648

[23] Y. Yang and X. Zheng, "Method for solution of the interaction between superconductor and permanent magnet," Journal of Applied Physics, vol. 101, no. 11, June 15 2007. [Online]. Available: https://doi.org/10.1063/1.2745082

[24] X. Wu and et al, "Modeling of hysteretic behavior of the levitation force between superconductor and permanent magnet," Physica C: Superconductivity, vol. 486, March 15 2013. [Online]. Available: https://doi.org/10.1016/j.physc.2012.12.006

[25] A. Sanchez and C. Navau, "Magnetic levitation of thin superconducting disks," Physica C: Superconductivity, vol. 275, no. 3, february 20 1997. [Online]. Available: https://doi.org/10.1016/ S0921-4534(96)00723-X

[26] A. Sanchez and C. Navau, "Levitation force between a superconductor and a permanent magnet with cylindrical symmetry," Physica C: Superconductivity and its Applications, vol. 364, November 2001. [Online]. Available: https://doi.org/10.1016/ S0921-4534(01)00796-1

[27] M. Qin, G. Li, H. Liu, S. Dou, and E. Brandt, "Calculation of the hysteretic force between a superconductor and a magnet," Physical Review B, vol. 66, no. 2, July 2002. [Online]. Available: http://dx.doi.org/10.1103/PhysRevB.66.024516

[28] D. Camacho, J. F. J. Mora, and X. Obradors, "Calculation of levitation forces in permanent magnet-superconductor systems using finite element analysis," Journal of Applied Physics, vol. 82, no. 3, August 1997. [Online]. Available: https://doi.org/10.1063/1.365924

[29] T. Akamatsu, H. Ueda, and A. Ishiyama, "Characteristics of levitating X-Y transporter using HTS bulks," IEEE Transactions on Applied Superconductivity, vol. 13, no. 2, july 2003. [Online]. Available: https://doi.org/10.1109/TASC.2003.813024

[30] C. Navau, N. del Valle, and A. Sanchez, "Macroscopic modeling of magnetization and levitation of hard type-II superconductors: The critical-state model," IEEE Transactions on Applied Superconductivity, vol. 23, no. 1, February 2013. [Online]. Available: https://doi.org/10. $1109 /$ TASC. 2012.2232916

[31] S. Valenzuela, G. Jorge, and E. Rodríguez, “Measuring the interaction force between a high temperature superconductor and a permanent magnet," American Journal of Physics, vol. 67, no. 11 November 1999. [Online]. Available: https://doi.org/10.1119/1.19160

[32] C. Bean, "Magnetization of high-field superconductors," Reviews of Moderns Physics, vol. 36, January 1964. [Online]. Available: https://doi.org/10.1103/RevModPhys.36.31
[33] C. Bean, "Magnetization of hard superconductors," Physical Review Letters, vol. 8, March 15 1962. [Online]. Available: https://doi.org/ 10.1103/PhysRevLett.8.250

[34] E. Brandt, "Rigid levitation and suspension of high-temperature superconductors by magnets," American Journal of Physics, vol. 58, no. 1, January 1990. [Online]. Available: https://doi.org/10.1119/1. 16317

[35] J. Jackson, Classical Electrodynamics, 3rd ed. USA: John Wiley \& Sons, Inc., 1999.

[36] J. Wu and H.Zhao, "Recent progress in fabrication, characterization, and application of hg-based oxide superconductors," in High Temperature Superconductors, R. Bhattacharya and M. Parans, Eds. Great Britain, UK: Wiley-VCH Verlag GmbH \& Co, 2010.

[37] K. Salama and S. Sathyamurthy, "Melt texturing of YBCO for high current applications," Applied Superconductivity, vol. 4, no. 10, October 1 1996. [Online]. Available: https://doi.org/10. 1016/S0964-1807(97)00039-2

[38] G. Goncalves and et al, "Experimental and theoretical levitation forces in a superconducting bearing for a real-scale maglev system," IEEE Transactions on Applied Superconductivity, vol. 21, no. 5, October 2011. [Online]. Available: https://doi.org/10.1109/ TASC.2011.2159114

[39] D. Dias, E. Silva, G. Sotelo, and R. Pestana, “Experimental validation of field cooling simulations for linear superconducting magnetic bearings," Superconductor Science and Technology, vol. 23, no. 7, June 2010. [Online]. Available: https://doi.org/10.1088/0953-2048/ 23/7/075013

[40] T. Matsushita, Flux Pinning in Superconductors, 2nd ed. New York, USA: Springer-Verlag Berlin Heidelberg, 2014.

[41] M. Pérez and A. Mariño, "Efectos del anclaje de flujo magnético en superconductores de YBCO (123) dopados con Ag," Momento, vol. 41, pp. 24-36, Dec. 2010.

[42] A. Jha and N. Khare, "Strongly enhanced pinning force density in $\mathrm{YBCO}^{-\mathrm{BaTiO}_{3}}$ nanocomposite superconductor," Physica C: Superconductivity, vol. 469, no. 14, July 15 2009. [Online]. Available: https://doi.org/10.1016/j.physc.2009.05.008

[43] A. Harabor, P. Rotaru, N.Harabor, P. Nozar, and A. Rotaru, "Orthorhombic YBCO-123 ceramic oxide superconductor: Structural, resistive and thermal properties," Ceramics International, vol. 45, no. 2, February 1 2019. [Online]. Available: https://doi.org/10.1016/j.ceramint.2018.07.272

[44] U. Gokay and M. Tepe, "Studies on structural and magnetic properties of melt textured growth $\mathrm{YBa}_{2} \mathrm{Cu}_{3} \mathrm{O}_{7-x}$ superconducting bulk materials," Journal of Physics: Conference Series, vol. 153, no. 1, 2009. [Online]. Available: https://doi.org/10.1088/1742-6596/ 153/1/012011

[45] S. Georgieva and T. Nedeltcheva, "Determination of the Oxygen Stoichiometry of $\mathrm{Y}_{1} \mathrm{Ba}_{2} \mathrm{Cu}_{3} \mathrm{O}_{Y}$ Superconductors with Different Oxygen Content," Journal of the University of Chemical Technology and Metallurgy, vol. 47, no. 1, pp. 91-96, Jan. 2012.

[46] T. Nedeltcheva, "Determination of oxygen stoichiometry in YBCO superconductors by spectrophotometry," Analytica Chimica Acta, vol. 312, no. 2, August 30 1995. [Online]. Available: https: //doi.org/10.1016/0003-2670(95)00237-T

[47] S. Degoy and et al, "Oxygen content of YBaCuO thin films," Physica C: Superconductivity, vol. 256, no. 3, January 10 1996. [Online]. Available: https://doi.org/10.1016/0921-4534(95)00666-4

[48] J. Hull and A. Cansiz, "Vertical and lateral forces between a permanent magnet and a high-temperature superconductor," Journal of Applied Physics, vol. 86, no. 11, August 1999. [Online]. Available: https://doi.org/10.1063/1.371703 